Review

\title{
Endovascular treatment for dural arteriovenous fistulas in the petroclival region
}

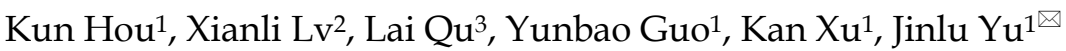 \\ 1. Department of Neurosurgery, The First Hospital of Jilin University, Changchun, 130021, China \\ 2. Department of Neurosurgery, Tsinghua Changgung Hospital of Tsinghua University, Beijing 102218, China \\ 3. Department of Intensive Care Unit, The First Hospital of Jilin University, Changchun, 130021, China \\ Kun Hou and Xianli Lv contribute equally to this manuscript and they are co-first authors. \\ $\square$ Corresponding author: Jinlu Yu. Department of Neurosurgery, The First Hospital of Jilin University, 1 Xinmin Avenue, Changchun 130021, China. Email: \\ jlyu@jlu.edu.cn, jinluyu@hotmail.com \\ (0) The author(s). This is an open access article distributed under the terms of the Creative Commons Attribution License (https://creativecommons.org/licenses/by/4.0/). \\ See http://ivyspring.com/terms for full terms and conditions.
}

Received: 2020.04.23; Accepted: 2020.10.07; Published: 2020.10.18

\begin{abstract}
Petroclival region dural arteriovenous fistulas (DAVFs) are rare and difficult lesions to manage. They often have very complex anatomical structures and can be further divided into the superior petrosal sinus, petrous apex, inferior petrosal sinus, upper clival, and upper clival epidural-osseous DAVFs. Most petroclival region DAVFs should be treated due to their high Cognard grades. Currently, endovascular treatment (EVT) has become the first-line therapeutic option for petroclival region DAVFs. But not all the petroclival region DAVFs could be cured with EVT. When the arterial feeders are large or the DAVF is adjacent to the venous sinus, the success rate may be higher. In petroclival region DAVFs, if EVT can be performed successfully, satisfactory outcome can be anticipated. However, there are some inadvertent complications, which include cranial nerve palsy, subsequent sinus thrombosis, and migration embolization of the internal carotid artery and vertebral artery. Currently, a review of the EVT of petroclival region DAVFs is lacking. In this article, we performed a review of the relevant literature on this issue. In addition, some illustrative cases would be provided to elaborate these specific entities.
\end{abstract}

Key words: Dural arteriovenous fistula; Petroclival region; Inferior petrosal sinus; Superior petrosal sinus; Endovascular treatment

\section{Introduction}

Intracranial dural arteriovenous fistulas (DAVFs) are abnormal connections between the dural arteries and dural venous sinuses or leptomeningeal veins [1]. DAVFs mostly involve the regions of the transverse, sigmoid, and cavernous sinuses. In rare circumstances, DAVFs could also be located at the petroclival region [2]. The petroclival region refers to the junction of the petrosal and occipital bones and is mainly confined to the upper clivus and the anterior third of the petrous pyramid in front of the internal acoustic meatus [3-5]. The petroclival region is illustrated in Figure 1A.

Petroclival region DAVFs have a variety of potential anatomical configurations and are defined by the involved venous sinus and plexus overlying the bony structures [6]. Petroclival region DAVFs are difficult to treat. Surgical removal often carries the risk of compromising the important neighboring neurovascular structures [7]. Although stereotactic radiosurgery is effective for intracranial DAVFs, it is not suitable for petroclival DAVFs. The DAVFs of petrosal region often present with hemorrhage and are at higher risk for rebleeding. Besides, the latent effective period is too long [8].

Currently, endovascular treatment (EVT) has become a first-line option for petroclival region DAVFs both for its effectiveness and low invasiveness [9]. However, EVT is not a one-size-fits-all solution for petroclival region DAVFs. In most of the cases, there are multiple arterial feeders, and no main sinus drainage, which could provide interventional venous route, is involved [10]. Considering their rarity and 
complexity, the petroclival region DAVFs still poses great challenge to both the neurosurgeons and neurointerventionalists. In order to further expound the EVT for petroclival region DAVFs, we performed a review of the relevant literature.

\section{Classification}

The petroclival region mainly refers to the area of the upper clivus and the anterior third of the petrous pyramid in front of the internal acoustic meatus $[3,4]$. The dural and venous structures in this area mainly include the superior petrosal sinus (SPS), the inferior petrosal sinus (IPS), and the basilar plexus (BP) [11-13]. Based on their positional and anatomical characteristics, the petroclival region DAVFs are classified into the SPS DAVF, IPS DAVF, petrous apex DAVF, upper clival DAVF, and upper clival epidural-osseous DAVF. Classification of the petroclival region DAVFs is illustrated in Figure 1B.

The SPS DAVF, also known as the petrous ridge DAVF, accounts for approximately $5 \%$ of all intracranial DAVFs [10, 14-16]. The petrous apex DAVF often involves the free edge of the tentorium [7, 17]. In Barnwell et al.'s study, the IPS DAVF accounts for approximately $6 \%$ of all intracranial DAVFs [18, 19]. Due to their similarity in angioarchitecture, DAVFs involving the inferior petroclival vein (IPCV) are often regarded as IPS DAVFs [18, 20,21].

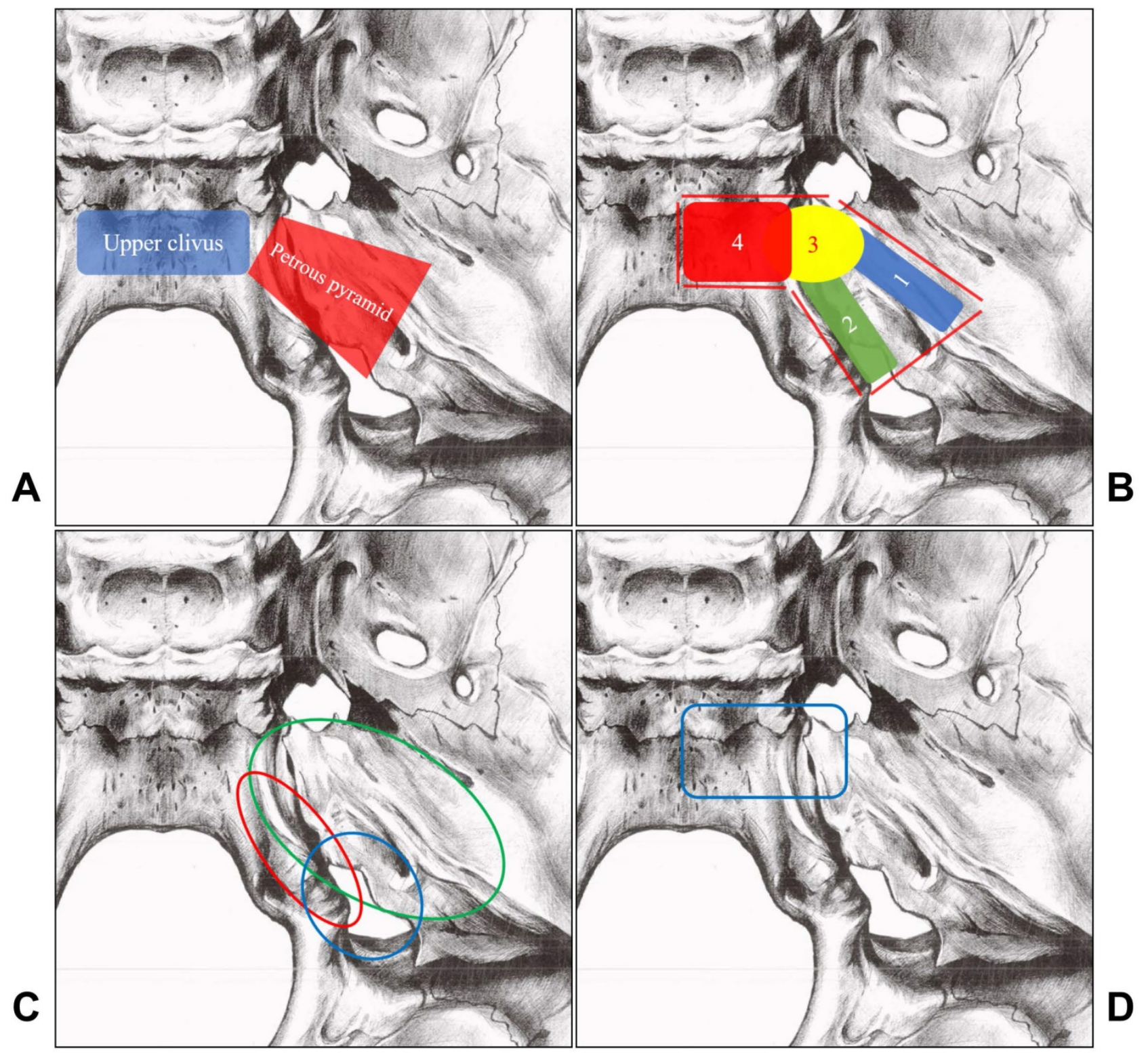

Figure 1. A, The petroclival region mainly includes the upper clivus (blue rectangle area) and the anterior third of the petrous pyramid (Red trapezoid area). B, Petrous region DAVFs include SPS DAVFs (No. 1 blue area), IPS DAVFs (No. 2 green area), petrous apex DAVFs (No. 3 yellow area), upper clival DAVFs (No. 4 red area), and upper clival epidural-osseous DAVFs (No. 4 red area). C, The arterial supply of the lateral petroclival region includes the MMA (green circle), the AphA (red circle), and the OA (blue circle). $\mathrm{D}$, The arteries supplying the petrous apex/upper clivus region dura are show in the blue rectangle area, the main feeding arteries are derived from the meningeal branches of the ICA. Abbreviations: AphA, ascending pharyngeal artery; DAVF, dural arteriovenous fistula; ICA, internal carotid artery; IPS, inferior petrosal sinus; MMA, the middle meningeal artery; OA, occipital artery; SPS, superior petrosal sinus. 
The Upper clival DAVF and upper clival epidural-osseous DAVF are rare. The two distinct entities are distinguished from each other mainly based on their fistula locations: the former is on the dura, the latter is on the wall of the dilated venous pouch of the intraosseous veins [22-24].

\section{Angioarchitecture and grading}

\section{Angioarchitecture}

\section{Feeding artery}

The normal dural supplying arteries in the petroclival region can be divided in two groups: the lateral petroclival and the petrous apex/upper clivus groups $[4,25]$.

\section{(i) Lateral petroclival region}

For the DAVFs in the lateral petroclival region, including SPS and IPS DAVFs, the main feeding arteries originate from the meningeal branches of the external carotid artery (ECA), such as the ascending pharyngeal artery (AphA), the occipital artery (OA), and the middle meningeal artery (MMA) $[10,14,16$, $18,21,26-28]$. In rare cases, the meningeal branches of the internal carotid artery (ICA)and vertebral artery (VA) can supply the lateral petroclival region DAVFs $[10,15,16,18,21,29]$. In addition, the superficial temporal artery and the meningeal branches of the maxillary artery can also be involved in IPS DAVFs $[18,19]$.

More specifically, the jugular branch and hypoglossal branches of the AphA supplies the lateral wall of the IPS [30]. The mastoid branch of the OA supplies the dura over the lateral portion of the posterior petrosal bone [31]. The petrosal branch and the posterior division of the MMA supplies the dura over the insertion of the tentorium along the petrous ridge and the SPS [25, 32]. The main arterial supply pattern to the lateral petroclival region dura is shown in Figure 1C.

\section{(ii) Petrous apex/upper clivus region}

For DAVFs in this region, the main feeding arteries are derived from the meningeal branches of the ICA $[7,15,17,22,33,34]$. The meningeal arteries of the ICA include the recurrent artery of the foramen lacerum, medial tentorial artery, lateral tentorial artery, dorsal meningeal artery, medial clival artery, and inferolateral trunk $[25,35,36]$. The meningeal branches of the maxillary artery can also be involved $[7,15,22]$. The arterial supply pattern to the petrous apex/upper clivus region dura is shown in Figure 1D.

Under rare circumstances, the anterior meningeal artery of the VA, the subarcuate artery of the anterior inferior cerebellar artery, and the tentorial branch of the posterior cerebral artery can also provide blood supply to the DAVFs in this region [23, $25,37-39]$. For the clival epidural-osseous DAVFs, in addition to the aforementioned feeding arteries, the posterior auricular artery, internal maxillary artery, superficial temporal artery, and the muscular-dural and the ascending cervical branches of the VA can also be involved [24].

In general, the feeding arteries of petroclival region DAVFs originate from the ipsilateral side, and occasionally they might originate from both the ipsilateral and contralateral sides [18]. In the condition of DAVFs, the blood-supplying range of the meningeal branches of the ECA, ICA, and VA becomes wider than in normal conditions. And these arteries also become unusually enlarged [21, 22].

\section{Venous drainage}

\section{(i) Normal venous drainage structure}

In the petroclival region, the posterior part of the cavernous sinus (CS), the SPS, the IPS, and the BP converge to form the petroclival venous confluence (PVC) [11-13]. The superior petrosal vein (SPV) empties into the SPS [40]. The BP is located between the periosteal and meningeal layers of the clivus and communicates with the CS, SPS, and IPS [41, 42]. The IPS drains venous blood from the PVC and the BP then empties into the junction of the sigmoid sinus and the superior jugular bulb [43].

\section{(ii) DAVF venous drainage patterns}

Different types of petroclival region DAVFs have different venous drainage patterns. The SPS DAVF usually drains into the SPV and its tributaries, and occasionally the CS can act as the venous drainage route [16, 26, 29, 44, 45]. Petrous apex DAVF mainly drains supratentorially into the Vein of Galen, the internal cerebral vein, and the straight sinus $[17,33$, 46]. The IPS DAVF has a similar venous drainage to that of the CS DAVF. It often drains retrogradely into the CS via the IPS and then out through the superior ophthalmic vein, and sometimes there is some antegrade flow into the sigmoid sinus [18, 21, 27, 28].

The venous drainage of the upper clival DVAF is from the clival veins to the CS and the superior ophthalmic vein $[22,34,47,48]$. It can also drain to the IPS or even the cortical vein. The venous drainage of the intraosseous DAVF is often through the adjacent sinus, such as the IPS, the jugular bulb, and the internal jugular vein $[23,24]$.

In addition, venous outflow obstruction is common in petroclival region DAVFs, contributing to the arterialization of the thin-walled pial veins, which increases the venous pressure, promotes the formation of venous ectasia, or leads to venous 
infarction [15-19, 21, 23, 26, 49, 50]. As illustrated in Fig 2, the enlarged petrosal vein and the Vein of Galen even lead to obstructive hydrocephalus. In rare circumstances, the venous drainage can even flow retrogradely into the spinal veins via the mesencephalic venous connections [14, 17, 33, 45, 51].

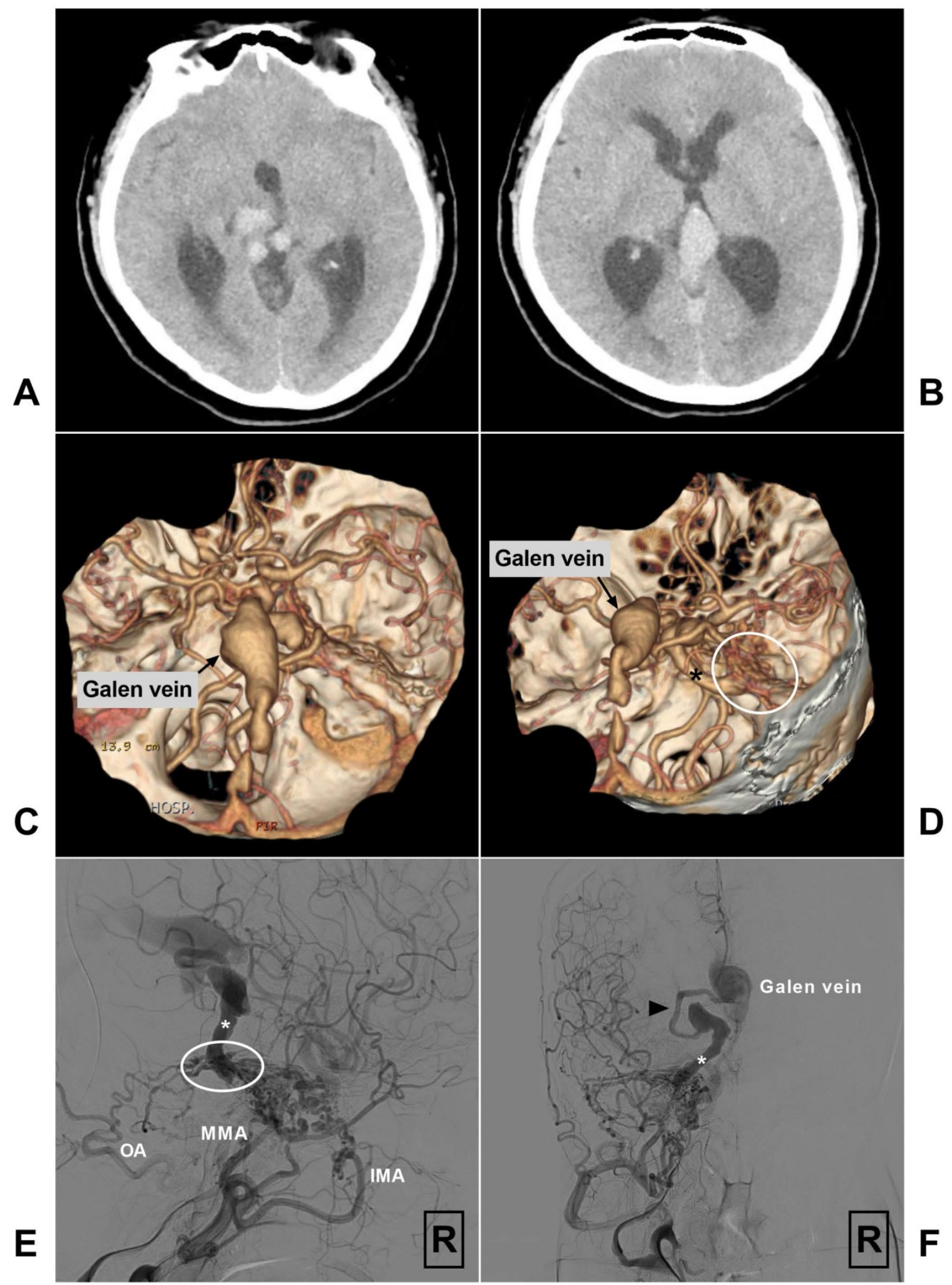

Figure 2. A-B, Head CT shows quadrigeminal cistern venous structure leading to obstructive hydrocephalus. C-D, CTA reveals a petroclival DAVF (encircled area) with enlarged petrosal vein (asterisk) and the Vein of Galen. E-F, Angiogram of the right ECA in lateral (E) and anteroposterior (F) views shows a SPS DAVF (encircled area) supplied by the IMA, MMA, and OA and drained retrogradely via the petrosal vein (asterisk) and pre-brainstem vein (arrow head) to the Vein of Galen. Abbreviations: CT, computed tomography; CTA, computed tomography angiography; DAVF, dural arteriovenous fistula; ECA, external carotid artery; IMA, internal maxillary artery; MMA, middle meningeal artery; OA, occipital artery, R, right; SPS: superior petrosal sinus. 


\section{Fistula point}

The fistula point of SPS DAVF is often located at the connection of the SPV and the SPS $[10,14,16]$. The fistula point of petrous apex DAVF is located at the dura mater of the petrous apex or the free edge of the tentorium $[7,17]$. The fistula point of IPS DAVF is often close to the jugular bulb [27]. The fistula point of the upper clival DAVF is at the clival dura mater on the clival venous plexus [22]. The fistula point of intraosseous DAVF is on the wall of the dilated venous pouch of the intraosseous diploic veins or the transosseous emissary veins [23]. The petroclival region DAVFs can be divided into the high-flow and low-flow types. The high-flow fistulas usually result from arterial overflow, whereas the low-flow fistulas may be caused by high venous pressure [46].

Angioarchitecture of the petroclival region DAVFs is summarized in Table 1.

Table 1. Angioarchitecture of petroclival region DAVFs

\begin{tabular}{|c|c|c|c|}
\hline Types & $\begin{array}{l}\text { Main } \\
\text { feeding } \\
\text { artery }\end{array}$ & Fistula point & Main venous drainage \\
\hline SPS DAVF & $\begin{array}{l}\text { AphA, } \\
\text { OA, and } \\
\text { MMA }\end{array}$ & $\begin{array}{l}\text { Dura at the } \\
\text { connection between } \\
\text { the SPV and the SPS }\end{array}$ & $\begin{array}{l}\text { SPV and its tributaries, and } \\
\text { occasionally the CS }\end{array}$ \\
\hline IPS DAVF & $\begin{array}{l}\text { AphA, } \\
\text { OA, and } \\
\text { MMA }\end{array}$ & $\begin{array}{l}\text { Dura close to the right } \\
\text { jugular bulb }\end{array}$ & $\begin{array}{l}\text { Retrograde flow through the } \\
\text { IPS to the CS, and sometimes } \\
\text { antegrade flow to the } \\
\text { sigmoid sinus }\end{array}$ \\
\hline $\begin{array}{l}\text { Petrous apex } \\
\text { DAVF }\end{array}$ & $\begin{array}{l}\text { Meningeal } \\
\text { branches } \\
\text { of the ICA }\end{array}$ & $\begin{array}{l}\text { Petrous apex dura or } \\
\text { the free edge of the } \\
\text { tentorium }\end{array}$ & $\begin{array}{l}\text { Vein of Galen, the internal } \\
\text { cerebral vein, and the straight } \\
\text { sinus }\end{array}$ \\
\hline $\begin{array}{l}\text { Upper clival } \\
\text { DAVF }\end{array}$ & $\begin{array}{l}\text { Meningeal } \\
\text { branches } \\
\text { of the ICA }\end{array}$ & $\begin{array}{l}\text { Clival dura on the } \\
\text { clival venous plexus }\end{array}$ & $\begin{array}{l}\text { CS or to the IPS and even to } \\
\text { the cortical vein }\end{array}$ \\
\hline $\begin{array}{l}\text { Upper clival } \\
\text { epidural-osseous } \\
\text { DAVF }\end{array}$ & $\begin{array}{l}\text { Meningeal } \\
\text { branches } \\
\text { of the ICA }\end{array}$ & $\begin{array}{l}\text { Wall of the } \\
\text { intraosseous diploic } \\
\text { veins or the } \\
\text { transosseous } \\
\text { emissary veins }\end{array}$ & $\begin{array}{l}\text { IPS, jugular bulb, and } \\
\text { internal jugular vein }\end{array}$ \\
\hline
\end{tabular}

Abbreviations: AphA, ascending pharyngeal artery; CS, cavernous sinus; DAVF, dural arteriovenous fistula; ICA, internal carotid artery; IPS, inferior petrosal sinus; MMA, the middle meningeal artery; OA, occipital artery; SPS, superior petrosal sinus; $\mathrm{SPV}$, superior petrosal vein.

\section{Grading}

SPS and petrous apex DAVFs often have retrograde pial venous drainage, deep cerebral venous drainage, and venous ectasia. Hence, they are often categorized as types III or IV according to the Cognard's classification and are prone to have aggressive clinical courses [7, 10, 15, 52]. IPS and upper clival DAVFs often drain antegradely into the venous sinuses, and they are prone to have lower Cognard's grades $[18,21,23,27,28]$. The clival epidural-osseous DAVF often drains into the adjacent sinuses, so its Cognard's grade belongs to types I and II in most cases [24].

\section{Outline of EVT}

Most petroclival region DAVFs should be treated due to their high Cognard's grades, especially for those with venous ectasia of alarming sizes [10]. Currently, EVT has become a first-line option for most intracranial DAVFs, which includes transarterial embolization (TAE) and transvenous embolization (TVE) [53]. The selection of TAE or TVE should be determined in a case by case approach, which is mainly based on the individual anatomic characteristics [48]. The goal of EVT is complete obliteration of the lesion [54]. To achieve definite obliteration via EVT, the embolic material has to plug the arteriovenous communication or seal the lumen of the draining venous structure [46].

Complete embolization is necessary. Though partial EVT can result in marked decrease in flow and venous hypertension, the risk of rebleeding remains unchanged [2]. Moreover, with mere occlusion of feeding arteries, the DAVFs are likely to recruit new feeders, even after a previous complete angiographic cure [52]. Currently, as a result of the development of new techniques and materials, particularly with the use of Onyx (Medtronic Neurovascular, Minneapolis, $\mathrm{MN}$ ), TAE has become a more effective option and represents the first-line option for many DAVFs [10, 14]. However, in some cases, TAE alone may be unsuccessful in obliterating the petroclival region DAVFs, because the feeding arteries are too tiny to permit super-selective embolization [10].

Currently, TVE is useful for intracranial DAVFs involving the major dural sinuses $[22,55]$. However, TVE for petroclival region DAVFs is difficult because the initial venous drainage mainly flows through the pial veins $[15,16]$. Therefore, TVE could only be tried in limited cases [10]. For some intracranial DAVFs, treatment with combined TAE and TVE is superior [56]. However, for the petroclival region DAVFs, the combined TAE and TVE approach is unnecessary in most cases. Of note, TVE after unsuccessful TAE or TAE after unsuccessful TVE does not belong to the combined treatment.

In summary, EVT cannot be readily used for all petroclival region DAVFs. When the arterial feeders are large or the DAVFs are adjacent to the venous sinuses, the success rate is high.

\section{Transarterial embolization}

TAE is difficult for petroclival region DAVFs and can only be performed in selected cases with large and straight arterial feeders [21]. During TAE, careful evaluation of the DAVF structure and dynamic blood flow change with 3-dimensional angiogram is necessary. Advancing the microcatheter more closely 
to the fistula site can increase the success rate and reduce the risk of inadvertent embolization of the non-targeted vessel [29].

The SPS, petrous apex, and upper clival DAVFs can be treated with TAE alone [7, 22, 33]. Of note, using Onyx can result in higher cure rate [17, 22]. Furthermore, the advance in improved flexibility, trackability, and shape retention of microcatheter design and the improvement of guidewire technology have permitted super-selective catheterization of more and more previously inaccessible arterial feeders [15]. For most of the intracranial DAVFs, MMA is the best route during TAE, and there is no exception for petroclival region DAVFs [57].

\section{Transarterial path}

For SPS and petrous apex DAVFs, the petrosquamous branch of the MMA is an effective transarterial path [10, 14, 21, 33, 45]. For instance, Alleyne et al. reported an SPS DAVF with TAE [26]. The microcatheter was advanced to the most distal branch of the posterior MMA and the SPS was completely occluded with n-butyl cyanoacrylate (NBCA).

In addition to the MMA, some other arteries can also be used, such as the mastoid branch of the OA, the neuromeningeal trunk of the AphA, and the anterior meningeal artery of the VA [10, 22, 45]. For instance, the upper clival DAVF can be completely embolized via the clival branch of the AphA [22]. However, TAE via other feeders than the MMA means a lower success rate and more risks $[10,22,45]$.

\section{Onyx and NBCA}

Onyx is widely used in TAE for its strong ability in penetrating the shunt and occluding the draining vein [22]. However, for the embolization of petroclival region DAVFs, Onyx is associated with higher risk of complications, because the Onyx would partially reflux during pushing forward [58, 59]. In contrast, NBCA tends to move forward during TAE and does not reflux [10, 45, 46]. However, NBCA may fail to penetrate deeply enough to completely occlude the DAVFs, because its polymerization is unpredictable and its adhesive properties place the patient at the risk of permanently retaining the microcatheter [14, 28, 60-62]. Therefore, the choosing of a specific embolic agent should depend on the specific angioarchitecture $[22,29,63]$.

In Fig 3, we present an unsuccessful case with TAE. An illustrative case of petroclival DAVF treated with successful TAE via the MMA is also presented in Fig 4.

\section{Transvenous embolization}

For petroclival region DAVFs, TVE may be a good option in some cases. SPS and IPS DAVFs may be good candidates because these DAVFs are adjacent to the SPS and IPS. For the TVE of SPS and IPS DAVFs, the detachable coils are effective in blocking the initial part of the draining vein $[15,16,18,28]$. Even after mere occlusion of the leptomeningeal vein to reduce venous pressure, the outflow of residual DAVF could be stopped, leading to subsequent venous thrombosis inside the dura [17, 45].

For instance, according to Seong et al.'s report, an SPS DAVF was completely occluded after a coil was pushed to the fistula site via the SPV [10]. In another case reported by Gentric et al., an IPS DAVF was coiled via the IPS after percutaneous puncture of the superior ophthalmic vein [27]. IPS DAVF can be occluded tranvenously even though the IPS is thrombosed [18].

Occasionally, for the upper clival DAVF, the draining clival venous structures can be embolized with coils via the IPS [48]. However, when the DAVFs empty directly into the clival veins rather than into the adjacent sinuses, transvenous coiling without occlusion of the fistulous sites may be ineffective [22, 47]. In intraosseous DAVF, the feeding arteries are centered on the wall of the dilated venous pouch that is located within the bone and communicate with the venous structures. Therefore, this type of DAVF could be completely occluded with TVE. For curative treatment, the venous pouch can be the target during endovascular treatment [23]. Rarely, for SPS DAVF, TVE is possible through a patent occipital sinus [16]. IPCV DAVF can also be treated with TVE [20].

However, for most petroclival region DAVFs, due to the absence of connection with the venous sinus, the occlusion of the downstream sinus, or significant venous stenosis near the junction of the draining vein and the sigmoid sinus, TVE is impossible [50]. TVE through the fragile pial veins might result in premature rupture of the draining veins $[15,16]$.

An illustrative case of petroclival DAVF treated with successful TVE is presented in Fig 5.

\section{Complications}

\section{Cranial nerve palsy}

The petroclival region contains some important cranial nerves. The petroclival region DAVFs often has intersecting arterial supply with these cranial nerves. Excessive reflux of liquid embolic agents during TAE of the petroclival region DAVFs could lead to cranial nerve palsy $[7,18,22]$. 


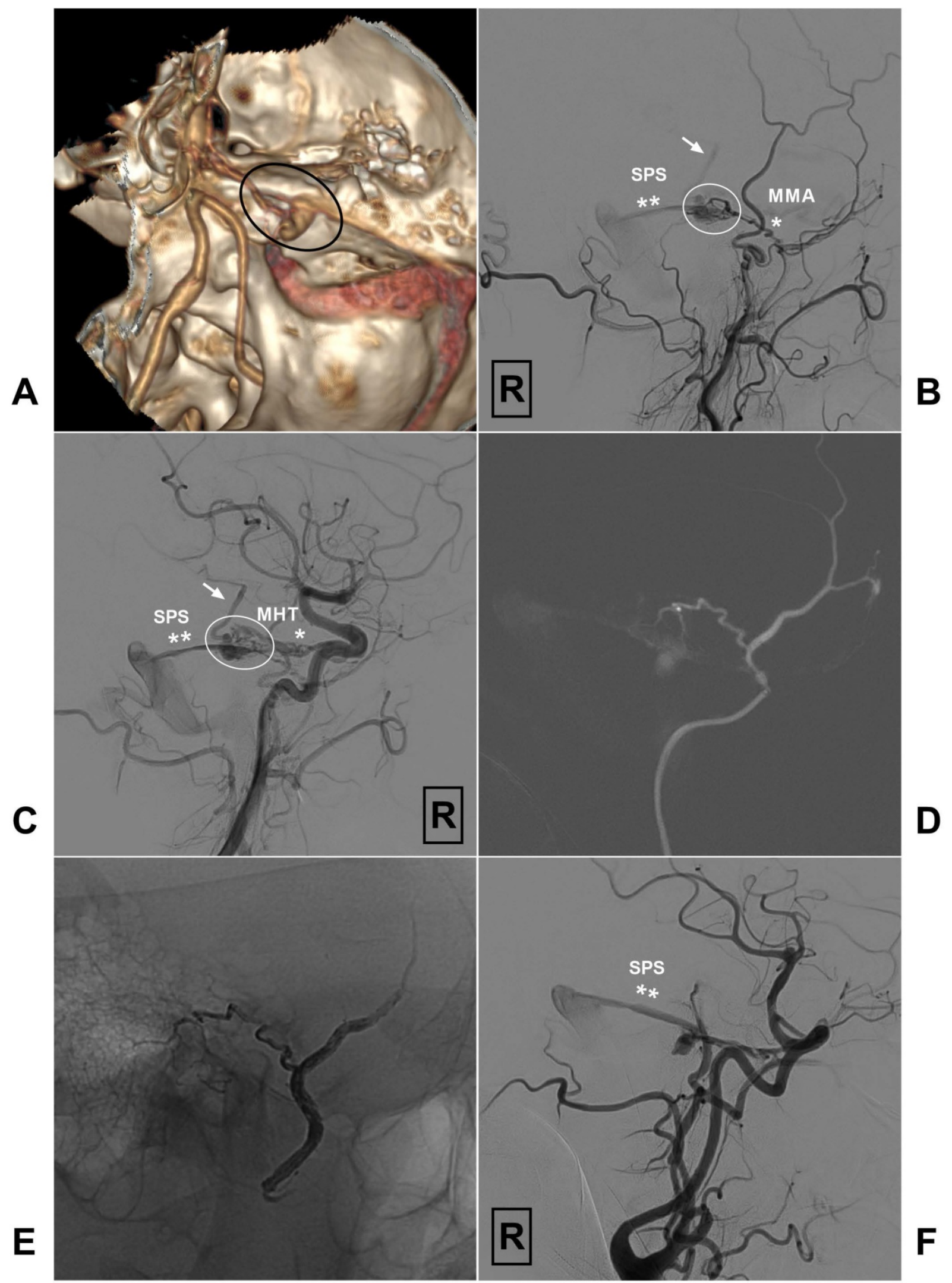

Figure 3. A, CTA reveals a petroclival DAVF (encircled area). B, Angiogram of the right ECA in lateral view shows the DAVF (encircled area) is supplied by the MMA (single asterisk) and drains to the SPS (double asterisks). Besides, retrograde venous drainage (arrow) to the brainstem is also noted. C, Angiogram of the right ICA in right anterior oblique view shows the DAVF (encircled area) also receives blood supply from the MHT (single asterisk) and drains to the SPS (double asterisks). Retrograde venous drainage (arrow) to the brainstem is also noted. D, Super-selective angiogram of the right MMA shows the branch supplying the DAVF is tortuous and enlarged. E, Onyx could not penetrate the fistula point during transarterial embolization of the DAVF via the MMA. F, Angiogram of the ICA shows the DAVF still has residual venous drainage via SPS (double asterisks). Abbreviations: CTA, computed tomography angiography; DAVF, dural arteriovenous fistula; ECA, external carotid artery; ICA, internal carotid artery; MHT, meningohypophyseal trunk; MMA, the middle meningeal artery; R, right; SPS: superior petrosal sinus. 


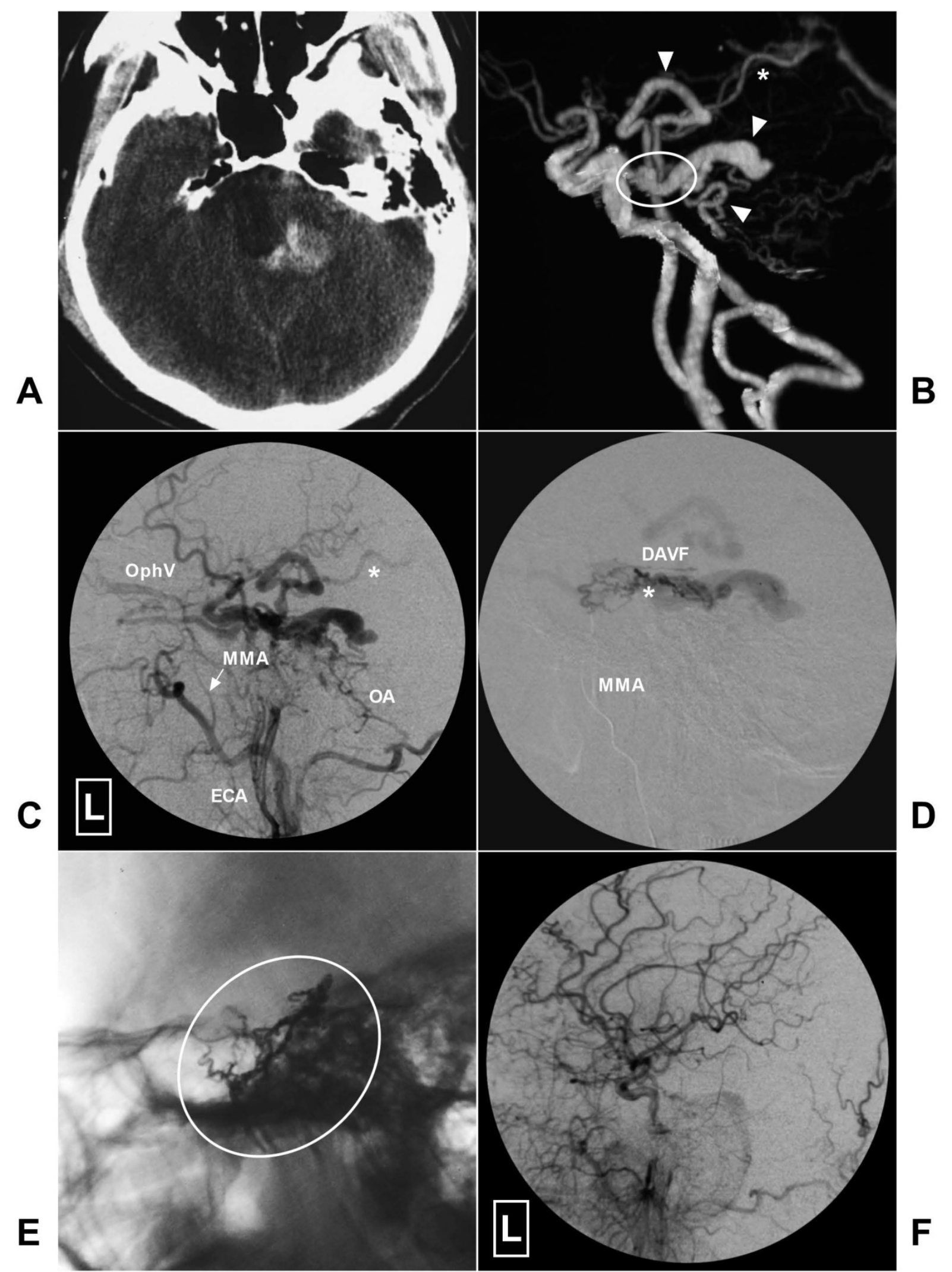

Figure 4. A, CT shows hemorrhage at the left side posterior to the brainstem. B, CTA reveals dilated venous structure (arrow heads) around the brainstem draining to the Vein of Galen (asterisk) indicating a petroclival DAVF (encircled area). C, Angiogram of the left ECA in lateral view shows the DAVF is mainly fed by the MMA (arrow) and OA and drains to the peri-brainstem and ophthalmic vein. Asterisk denotes the vein drains to the Vein of Galen. D, Super-selective angiogram via microcatheter shows the DAVF. Asterisk denotes the fistula point. E, X-ray of the cranium reveals Onyx casting (encircled area) through the MMA. F, Angiogram of the left CCA in lateral view after EVT shows the DAVF is completely obliterated. Abbreviations: CCA, common carotid artery; CT, computed tomography; CTA, computed tomography angiography; DAVF, dural arteriovenous fistula; ECA, external carotid artery; L, left; MMA, middle meningeal artery; OA, occipital artery; OphV, ophthalmic vein. 


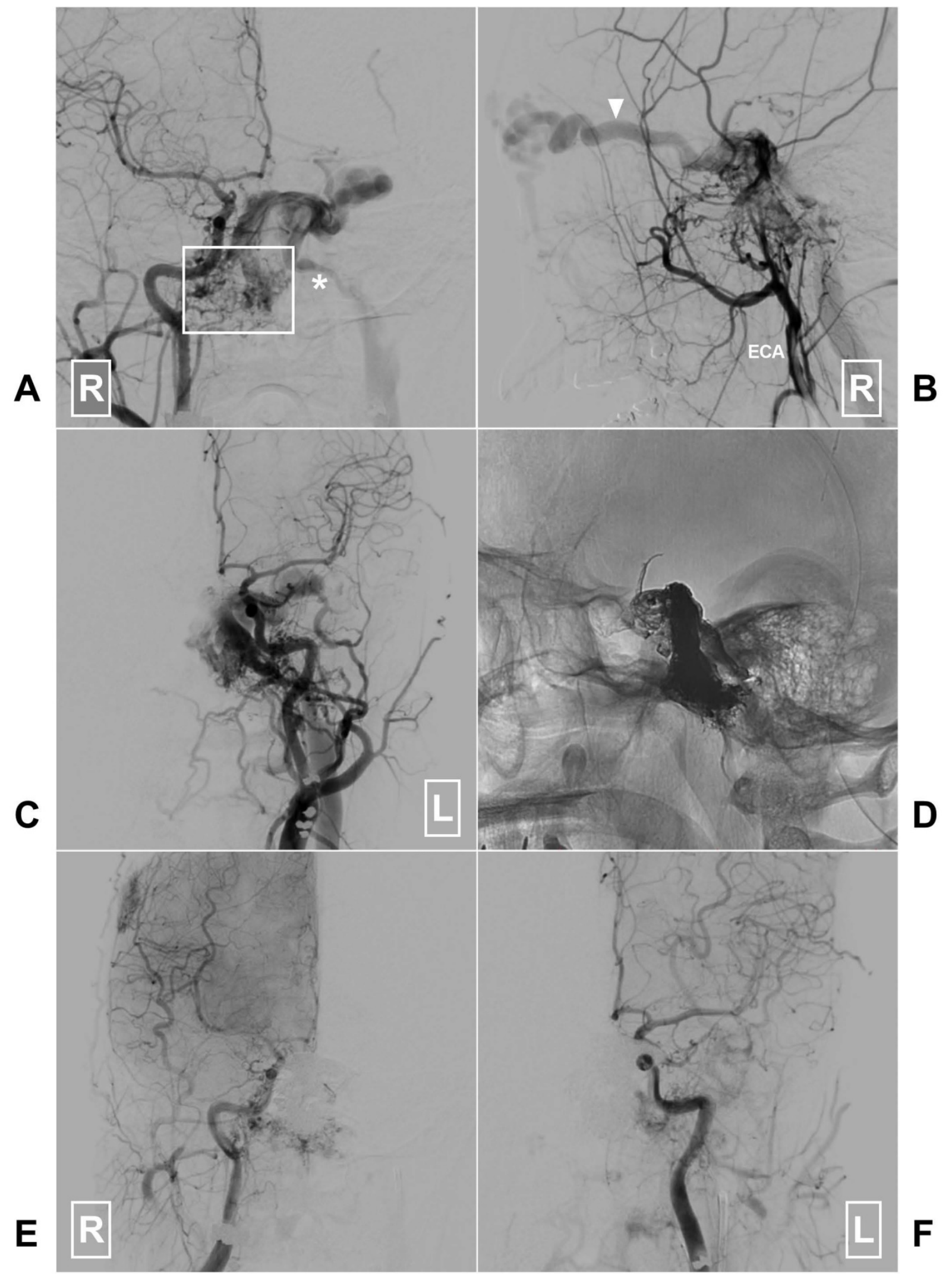

Figure 5. A, Angiogram of the right CCA in AP view reveals a clival DAVF (rectangle) draining to the contralateral IJV (asterisk) via the sigmoid sinus. B, Angiogram of the right ECA in lateral view shows there are multiple tiny feeding arteries. Arrow head denotes the ophthalmic vein drainage. C, Angiogram of the left CCA in AP view shows branches of the left ECA also supply the DAVF. D, X-ray of the cranium shows the Onyx casting after embolization of the through the left IJV. E-F, Angiogram of the right and left CCAs in AP view shows the DAVF is completely obliterated. Abbreviations: AP, anteroposterior; CCA, common carotid artery; DAVF, dural arteriovenous fistula; ECA, external carotid artery; IJV, internal jugular vein; L: left; R, right. 


\section{Venous sinus thrombosis}

After EVT of the petroclival region DAVFs, the associated sinus might experience subsequent thrombosis. For instance, in Barnwell et al.'s study, one patient developed extensive thrombosis of the ipsilateral transverse-sigmoid sinus and the jugular bulb 1 week after the embolization [18].

\section{Migration embolization}

At the petroclival region, there are many dangerous anastomoses. Therefore, before TAE, careful preoperative evaluation of the super-selective angiogram is necessary to identify potential collaterals to the ICA and the VA. Migration embolization of the ICA and the VA should be avoided [18].

\section{Prognosis}

In petroclival region DAVFs, if EVT can be performed successfully, a satisfactory outcome is anticipated [15, 33]. However, only a certain proportion of the patients could be successfully treated with EVT. For instance, in $\mathrm{Ng}$ et al.'s study, only 4 of the 14 patients (22\%) underwent successful TAE and TVE without adjunctive surgery [15]. Compared with TAE, TVE can result in higher cure rate. In Barnwell et al.'s report, 5 of the 6 patients received successful TVE [18].

\section{Summary}

Petroclival region DAVFs are rare and often have very complex anatomical structures. They can be further divided into the SPS, petrous apex, IPS, upper clival, and upper clival epidural-osseous DAVFs. Most petroclival region DAVFs should be treated due to their high Cognard grades.

Currently, EVT has become the first-line therapeutic option for petroclival region DAVFs. But not all the petroclival region DAVFs could be cured with EVT. When the arterial feeders are large or the DAVF is adjacent to the venous sinus, the success rate may be higher.

In petroclival region DAVFs, if EVT can be performed successfully, satisfactory outcomes can be anticipated. However, there are some inadvertent complications, which include cranial nerve palsy, subsequent sinus thrombosis, and migration embolization of the ICA and the VA.

\section{Acknowledgements}

\section{Informed consent}

Informed consent was obtained from all individual participants included in the study.

\section{Competing Interests}

The authors have declared that no competing interest exists.

\section{References}

1. Hou K, Ji T, Guo Y, Xu B, Xu K, Yu J. Current Status of Endovascular Treatment for Dural Arteriovenous Fistulas in the Superior Sagittal Sinus Region: A Systematic Review of the Literature. World Neurosurg. 2019; 122: 133-43.

2. Alturki AY, Enriquez-Marulanda A, Schmalz P, Ogilvy CS, Thomas AJ. Transarterial Onyx Embolization of Bilateral Transverse-Sigmoid Dural Arteriovenous Malformation with Transvenous Balloon Assist-Initial U.S. Experience with Copernic RC Venous Remodeling Balloon. World Neurosurg. 2018; 109: 398-402.

3. Fournier HD, Mercier P, Roche PH. Surgical anatomy of the petrous apex and petroclival region. Adv Tech Stand Neurosurg. 2007; 32: 91-146.

4. Tedeschi H, Rhoton AL, Jr. Lateral approaches to the petroclival region. Surg Neurol. 1994; 41: 180-216.

5. Tong D, Chen X, Lv X, Li K, Xu K, Yu J. Current status of endovascular treatment for dural arteriovenous fistulae in the tentorial middle region: a literature review. Acta neurologica Belgica. 2019; 119: 5-14.

6. Freeman JL, Sampath R, Quattlebaum SC, Casey MA, Folzenlogen ZA Ramakrishnan VR, et al. Expanding the endoscopic transpterygoid corridor to the petroclival region: anatomical study and volumetric comparative analysis. J Neurosurg. 2017; p: 1-10.

7. Westermaier T, Bendszus M, Solymosi L, Roosen K, Ernestus RI. Surgical treatment of dural arteriovenous fistulas of the petrous apex. World Neurosurg. 2012; 77(591 e):7-13.

8. O'Leary S, Hodgson TJ, Coley SC, Kemeny AA, Radatz MW. Intracranial dural arteriovenous malformations: results of stereotactic radiosurgery in 17 patients. Clin Oncol (R Coll Radiol). 2002; 14: 97-102.

9. Velat GJ, Reavey-Cantwell JF, Sistrom C, Smullen D, Fautheree GL, Whiting J, et al. Comparison of N-butyl cyanoacrylate and onyx for the embolization of intracranial arteriovenous malformations: analysis of fluoroscopy and procedure times. Neurosurgery. 2008; 63(ONS7):3-8; discussion ONS8-80.

10. Seong SO, David $\mathrm{C}$, Choi IS. Bilateral petrous ridge dural arteriovenous malformations treated by a combination of endovascular embolization and surgical excision. A case report. Interv Neuroradiol. 2006; 12: 269-75.

11. Destrieux C, Velut $S$, Kakou MK, Lefrancq T, Arbeille B, Santini JJ. A new concept in Dorello's canal microanatomy: the petroclival venous confluence. J Neurosurg. 1997; 87: 67-72.

12. Ozveren MF, Uchida K, Aiso S, Kawase T. Meningovenous structures of the petroclival region: clinical importance for surgery and intravascular surgery. Neurosurgery. 2002; 50: 829-36; discussion 36-7.

13. Ozgur A, Esen K, Kara E, Temel GO. Visualization of the Abducens Nerve in its Petroclival Segment Using Contrast-Enhanced FIESTA MRI: The Size of the Petroclival Venous Confluence Affects Detectability. Clin Neuroradiol. 2017; 27:97-103.

14. Kim HJ, Choi IS. Serious myelopathy due to magnetic resonance imaging-occult arteriovenous fistula: Case report of petrous ridge dural arteriovenous fistula. Interv Neuroradiol. 2015; 21: 609-12.

15. Ng PP, Halbach VV, Quinn R, Balousek P, Caragine LP, Dowd CF, et al. Endovascular treatment for dural arteriovenous fistulae of the superior petrosal sinus. Neurosurgery. 2003; 53: 25-32; discussion -3.

16. Branco G, Takahashi A, Ezura M, Yoshida M, Yoshimoto T. Dural arteriovenous shunt involving the superior petrosal sinus: presentation and treatment by transvenous embolisation via the occipital and transverse sinuses. Neuroradiology. 1997; 39: 67-70

17. Lewis AI, Rosenblatt SS, Tew JM, Jr. Surgical management of deep-seated dural arteriovenous malformations. J Neurosurg. 1997; 87: 198-206.

18. Barnwell SL, Halbach VV, Dowd CF, Higashida RT, Hieshima GB. Dural arteriovenous fistulas involving the inferior petrosal sinus: angiographic findings in six patients. AJNR Am J Neuroradiol. 1990; 11: 511-6.

19. Mironov A. Dural arteriovenous fistula of the inferior petrosal sinus producing contralateral exophthalmus. Neuroradiology. 1994; 36: 619-21.

20. Sugiura Y, Nishizawa S. Arteriovenous fistula involving the inferior petroclival vein--case report. Neurol Med Chir (Tokyo). 2011 : 51: 45-7.

21. Yamada M, Miyasaka Y, Kitahara Y, Yada K, Kan S. Dural arteriovenous malformation involving the inferior petrosal sinus--case report. Neurol Med Chir (Tokyo). 1994; 34: 300-3.

22. Shi ZS, Ziegler J, Gonzalez NR, Feng L, Tateshima S, Jahan R, et al. Transarterial embolization of clival dural arteriovenous fistulae using liquid embolic agents. Neurosurgery. 2008; 62:408-15; discussion 15.

23. Jung C, Kwon BJ, Kwon OK, Baik SK, Han MH, Kim JE, et al. Intraosseous cranial dural arteriovenous fistula treated with transvenous embolization. AJNR Am J Neuroradiol. 2009; 30: 1173-7.

24. Lee CC, Chen CJ, Chen SC, Yang HC, Lin CJ, Wu CC, et al. Gamma Knife surgery for clival epidural-osseous dural arteriovenous fistulas. J Neurosurg. 2018; 128: 1364-71. 
25. Martins C, Yasuda A, Campero A, Ulm AJ, Tanriover N, Rhoton A, Jr. Microsurgical anatomy of the dural arteries. Neurosurgery. 2005; 56:211-51; discussion -51 .

26. Alleyne $\mathrm{CH}$, Jr., Numaguchi Z, Wang HZ. Transarterial Embolisation of Dural Arteriovenous Fistula Involving an Isolated Segment of the Superior Petrosal Sinus. A Case report. Interv Neuroradiol. 2000; 6: 337-41.

27. Gentric JC, Ferre JC, Raoult H, Eugene F, Gauvrit JY. Endovascular treatment of inferior petrosal sinus dural arteriovenous fistula via percutaneous puncture of the superior ophthalmic vein. J Neuroradiol. 2013; 40: 144-6.

28. Kato S, Fujii M, Tominaga $T$, Fujisawa $H$, Suzuki M. [A case of dural arteriovenous fistula of the inferior petrosal sinus successfully treated by transarterial and transvenous embolizations]. No Shinkei Geka. 2002; 30: 981-4.

29. Ishihara $H$, Ishihara $S$, Kanazawa $R$, Kohyama $S$, Yamane F, Ogawa M, et al. [Transarterial NBCA embolization with transvenous partial outflow obstruction for superior petrosal sinus dural arteriovenous fistula: a case report]. No Shinkei Geka. 2007; 35: 1157-62.

30. Hacein-Bey L, Daniels DL, Ulmer JL, Mark LP, Smith MM, Strottmann JM, et al. The ascending pharyngeal artery: branches, anastomoses, and clinical significance. AJNR Am J Neuroradiol. 2002; 23: 1246-56.

31. Alvernia JE, Fraser K, Lanzino G. The occipital artery: a microanatomical study. Neurosurgery. 2006; 58(ONS):114-22; discussion ONS-22.

32. Yu J, Guo Y, Xu B, Xu K. Clinical importance of the middle meningeal artery: A review of the literature. Int J Med Sci. 2016; 13: 790-9.

33. Murphy M, Van Gompel JJ. Medullary venous hypertension secondary to a petrous apex dural arteriovenous fistula: a case report. Case Rep Neurol. 2012; 4: 187-93.

34. Gist TL, Rangel-Castilla L, Krishna C, Roman GC, Cech DA, Diaz O. Endovascular management of six simultaneous intracranial dural arteriovenous fistulas in a single patient. J Neurointerv Surg. 2014; 6: e16.

35. Gioppo A, Farago G, Caldiera V, Caputi L, Cusin A, Ciceri E. Medial Tentorial Dural Arteriovenous Fistula Embolization: Single Experience with Embolic Liquid Polymer SQUID and Review of the Literature. World Neurosurg. 2017; 107: 1050 e1- e7.

36. Peltier J, Fichten A, Havet E, Foulon P, Page C, Le Gars D. Microsurgical anatomy of the medial tentorial artery of Bernasconi-Cassinari. Surg Radiol Anat. 2010; 32: 919-25.

37. Warren DT, Warren MD, Malfair D, Akagami R. An incidence of anteroinferior cerebellar artery/posteroinferior cerebellar artery anatomic variants penetrating the subarcuate fossa dura: operative technique and identification with 3-dimensional fast imaging employing steady-state acquisition magnetic resonance imaging. Neurosurgery. 2010; 66: 199-203; discussion 4.

38. Tanriover $\mathrm{N}$, Rhoton $\mathrm{AL}$, Jr. The anteroinferior cerebellar artery embedded in the subarcuate fossa: a rare anomaly and its clinical significance. Neurosurgery. 2005; 57: 314-9; discussion -9.

39. Umeoka K, Takusakawa Y, Kominami S, Kobayashi S, Morita A. The meningeal branches of the superior cerebellar artery: a surgical observation study. J Neurosurg. 2016; 124: 244-7.

40. Tanriover N, Abe H, Rhoton AL, Jr., Kawashima M, Sanus GZ, Akar Z. Microsurgical anatomy of the superior petrosal venous complex: new classifications and implications for subtemporal transtentorial and retrosigmoid suprameatal approaches. J Neurosurg. 2007; 106: 1041-50.

41. Tubbs RS, Hansasuta A, Loukas M, Louis RG, Jr., Shoja MM, Salter EG, et al. The basilar venous plexus. Clin Anat. 2007; 20: 755-9.

42. Mizutani K, Akiyama T, Yoshida K, Toda M. Skull Base Venous Anatomy Associated with Endoscopic Skull Base Neurosurgery: A Literature Review. World Neurosurg. 2018; 120: 405-14.

43. Mortazavi MM, Griessenauer CJ, Krishnamurthy S, Verma K, Loukas M, Tubbs RS. The inferior petrosal sinus: a comprehensive review with emphasis on clinical implications. Childs Nerv Syst. 2014; 30: 831-4.

44. Lawton MT, Sanchez-Mejia RO, Pham D, Tan J, Halbach VV. Tentorial dural arteriovenous fistulae: operative strategies and microsurgical results for six types. Neurosurgery. 2008; 62: 110-24; discussion 24-5.

45. Hwang G, Kang HS, Oh CW, Kwon OK. Surgical obliteration in superior petrosal sinus dural arteriovenous fistula. J Korean Neurosurg Soc. 2011; 49: 222-5.

46. Pichierri A, Delfini R. Incisural and superior petrous dural arteriovenous fistulas: a contemporary perspective. World Neurosurg. 2012; 77: 472-4.

47. Urdaneta-Moncada A, Feng L, Chen J. Occlusion of a clival dural arteriovenous fistula using a novel approach through the foramen ovale. J Neurointerv Surg. 2013; 5: e46.

48. Pouw AE, Rabin RL, Karanjia R, Bababeygy SR, Amar AP, Sadun AA. Angioarchitectural evolution of clival dural arteriovenous fistulas in two patients. Case Rep Ophthalmol. 2015; 6: 93-100.

49. Nishino A, Sakurai $Y$, Takahashi A, Satoh H, Niizuma H, Kayama T, et al. [Superior petrosal sinus dural arteriovenous malformation with varix indenting brain stem--report of a case and review of the literature]. No To Shinkei. 1991; 43: 62-9.

50. Kimura T, Shojima M, Koizumi T, Fukaya S, Ichikawa Y, Morita A. Surgical treatment of a dural arteriovenous fistula in the superior petrosal sinus of an elderly patient with minimal suboccipital craniotomy: case report. Neurol Med Chir (Tokyo). 2009; 49: 465-7.
51. Brunet $E$, Tache $R$, Lafitte F, Piotin M, Miaux $Y$, Martin-Duverneuil N, et al. [Intracranial dural arteriovenous fistula with perimedullary venous drainage]. J Neuroradiol. 1998; 25: 103-10.

52. Awad IA, Little JR, Akarawi WP, Ahl J. Intracranial dural arteriovenous malformations: factors predisposing to an aggressive neurological course. J Neurosurg. 1990; 72: 839-50.

53. Luo $\mathrm{CB}$, Chang FC, Teng MM. Update of embolization of intracranial dural arteriovenous fistula. J Chin Med Assoc. 2014; 77: 610-7.

54. Gandhi D, Chen J, Pearl M, Huang J, Gemmete JJ, Kathuria S. Intracranial dural arteriovenous fistulas: classification, imaging findings, and treatment. AJNR Am J Neuroradiol. 2012; 33: 1007-13.

55. Kerolus MG, Chung J, Munich SA, Matsuda Y, Okada H, Lopes DK. An Onyx tunnel: reconstructive transvenous balloon-assisted Onyx embolization for dural arteriovenous fistula of the transverse-sigmoid sinus. J Neurosurg. 2017; p:1-6.

56. Natarajan SK, Ghodke B, Kim LJ, Hallam DK, Britz GW, Sekhar LN. Multimodality treatment of intracranial dural arteriovenous fistulas in the Onyx era: a single center experience. World Neurosurg. 2010; 73: 365-79.

57. Griessenauer CJ, He L, Salem M, Chua MH, Ogilvy CS, Thomas AJ. Middle meningeal artery: Gateway for effective transarterial Onyx embolization of dural arteriovenous fistulas. Clin Anat. 2016; 29: 718-28.

58. Lee B, Mehta VA, Amar AP, Tenser MS, Mack WJ. Transarterial embolization of an anterior fossa cranial base dural arteriovenous fistula. Neurosurg Focus. 2014; 37: 1.

59. Johnson CS, Chiu A, Cheung A, Wenderoth J. Embolization of cranial dural arteriovenous fistulas in the liquid embolic era: A Sydney experience. J Clin Neurosci. 2018; 49: 62-70.

60. Agid R, Terbrugge K, Rodesch G, Andersson T, Soderman M. Management strategies for anterior cranial fossa (ethmoidal) dural arteriovenous fistulas with an emphasis on endovascular treatment. J Neurosurg. 2009; 110: 79-84.

61. Tahon F, Salkine F, Amsalem Y, Aguettaz P, Lamy B, Turiman F. Dural arteriovenous fistula of the anterior fossa treated with the Onyx liquid embolic system and the Sonic microcatheter. Neuroradiology. 2008; 50: 429-32.

62. Katsaridis V, Papagiannaki C, Violaris C. Endovascular treatment of a bilateral ophthalmic-ethmoidal artery dural arteriovenous fistula. J Neuroophthalmol. 2007; 27: 281-4.

63. Mack WJ, Gonzalez NR, Jahan R, Vinuela F. Endovascular management of anterior cranial fossa dural arteriovenous malformations. A technical report and anatomical discussion. Interv Neuroradiol. 2011; 17: 93-103. 